\title{
PENGARUH PEMANFAATAN BUKU SEKOLAH ELEKTRONIK DAN MOTIVASI BELAJAR TERHADAP PRESTASI BELAJAR SISWA
}

\author{
Lalu Muh. Nurul Wahyu \\ Program Pascasarjana Universitas Negeri Malang, Jalan Semarang 5 Malang 65145 \\ Email: nurulwahyu74@yahoo.com
}

\begin{abstract}
The Effect of Buku Sekolah Elektronik (BSE) Utilization and Learning Motivation on IPS (Social Science) Achievement of Students. The results indicated that: (1) there is a difference in IPS achievement between students taught by BSE in classical and small groups; (2) there is a difference in IPS achievement between high motivated and low motivated students taught by BSE in a classical group; (3) there is a difference in IPS achievement between high motivated and low motivated students taught by BSE in small group; (4) there is a difference in IPS achievement between students taught by BSE in classical and small groups based on their high motivation; (5) there is a difference in IPS achievement between students taught by BSE in classical and small groups based on their low motivation; (6) there is an interaction between BSE utilization and learning motivation toward student achievement; and (7) students' perceptions about BSE utilization on the ease of operating the computer is $75 \%$, on the interest of using BSE is $79 \%$, and on the preference of using BSE is $80 \%$.
\end{abstract}

Keywords: electronic book, learning motivation, achievement

\begin{abstract}
Abstrak: Pengaruh Pemanfaatan Buku Sekolah Elektronik (BSE) dan Motivasi Belajar Terhadap Prestasi Belajar IPS Siswa. Hasil dari penelitian menunjukkan bahwa: (1) ada perbedaan prestasi belajar IPS antara siswa yang diajar dengan BSE secara klasikal dengan kelompok kecil; (2) ada perbedaan prestasi belajar IPS siswa yang diajar dengan BSE secara klasikal antara siswa bermotivasi tinggi dan bermotivasi rendah; (3) ada perbedaan prestasi belajar IPS siswa yang diajar dengan BSE secara kelompok kecil antara siswa bermotivasi tinggi dan bermotivasi rendah; (4) ada perbedaan prestasi belajar IPS antara siswa yang diajar dengan BSE secara klasikal dan kelompok kecil dilihat dari motivasi tinggi; (5) ada perbedaan prestasi belajar IPS antara siswa yang diajar dengan BSE secara klasikal dan kelompok kecil dilihat dari motivasi rendah; (6) ada interaksi antara pemanfaatan BSE dengan motivasi belajar terhadap prestasi belajar siswa; dan (7) persepsi siswa terhadap penggunaaan BSE pada aspek kemudahan mengoperasikan komputer adalah sebesar $75 \%$, pada aspek ketertarikan sebesar 79\%, dan pada aspek kesukaan sebesar $80 \%$.
\end{abstract}

Kata kunci: buku sekolah elektronik, motivasi belajar, prestasi belajar

Ilmu pengetahuan dan teknologi saat ini berkembang dengan sangat pesat. Berbagai update dan upgrade teknologi telah menembus ruang dan waktu sehingga dunia menjelma menjadi sebuah kampung global (global village) yang saling berinteraksi. Hal ini menjadi tantangan dan penunjang bagi dunia pendidikan, khususnya pada peningkatan proses pembelajaran, dimana teknologi digunakan dalam penyampaian materi, metode ajar, dan media pembelajaran. Dengan keadaan demikian, kemajuan teknologi dapat dimanfaatkan agar kegiatan belajar menjadi lebih efektif dan efesien. Penggunaan media yang efektif akan meningkatkan kualitas proses pembelajaran, yang pada akhirnya dapat meningkatkan kualitas hasil pembelajaran. Buku Sekolah Elektronik (BSE) merupakan inisiatif dari Kementerian Pendidikan Nasional yang bertujuan menyediakan buku ajar elektronik (e-book) untuk tingkat pendidikan dari SD, SMP, SMA, dan SMK. BSE terdiri dari buku-buku pelajaran yang dinyatakan telah memenuhi standar nasional pendidikan oleh BSNP (Irawan, dkk., 2010). 
Buku yang hak ciptanya telah dibeli pemerintah meliputi buku mata pelajaran Bahasa Indonesia, Bahasa Inggris, Ilmu Pengetahuan Sosial, Biologi, Ilmu Pengetahuan Alam, Pendidikan Kewarganegaraan, Ekonomi, Fisika, Geografi, Sejarah, Kimia, dan Matematika untuk jenjang pendidikan dasar dan menengah (Irawan, dkk., 2010). Motivasi belajar pada dasarnya merupakan bagian dari motivasi secara umum (Gunawan, 2007). Untuk itu akan lebih jelas apabila dalam mengkajinya dari motivasi secara umum. Motivasi merupakan suatu penggerak atau dorongan yang terdapat dalam diri manusia yang dapat menimbulkan, mengarahkan, dan mengorganisasikan tingkah lakunya (Gunawan, 2007). Hal ini terkait dengan upaya untuk memenuhi kebutuhan yang dirasakan, baik kebutuhan fisik maupun kebutuhan rohani. Dalam kaitannya dengan kegiatan belajar, maka motivasi belajar berarti keseluruhan daya penggerak di dalam diri peserta didik yang dapat menimbulkan, menjamin, dan memberikan arah pada kegiatan belajar, guna mencapai tujuan belajar yang diharapkan. Dengan motivasi belajar, maka peserta didik mempunyai intensitas dan kesinambungan dalam proses pembelajaran yang diikuti (Gunawan, 2007).

Hasil belajar siswa dipengaruhi oleh waktu (time) dan kesempatan (engagement). Waktu dan kesempatan yang dimiliki oleh masing-masing siswa berbeda sehingga berpengaruh terhadap perbedaan hasil belajar siswa (Gunawan, dkk., 2014). Siswa yang memberikan lebih banyak waktu dan kesempatan untuk belajar cenderung memiliki hasil belajar yang baik. Tingkat kepandaian seseorang sangat ditentukan dengan waktu dan kesempatan. Siswa akan mampu mengerjakan tugas dengan lebih baik jika diberikan waktu dan kesempatan yang cukup. Siswa yang lebih pandai memiliki kemungkinan mengerjakan tugas lebih singkat daripada siswa yang kurang pandai, sehingga, dosen harus memiliki kemampuan mengajar siswa secara individual dan mengenali karakteristik masing-masing siswa sehingga kegiatan pembelajaran dapat berjalan secara optimal (Gunawan, dkk., 2014).

\section{METODE}

Penelitian ini menggunakan pendekatan kuantitatif dengan metode eksperimen semu, dan rancangan faktorial $2 \times 2$ dengan pretest-postest nonequivalent control group. Populasi penelitian adalah siswa kelas IVa dan IVb di SDN 4 Praya. Sampel diambil secara acak (random). Instrumen yang digunakan dalam penelitian adalah tes hasil belajar, angket motivasi belajar dengan model ARCS dan angket respons compact disk (CD) komputer BSE. Uji coba instrumen penelitian dilakukan dengan validasi butir soal menggunakan rumus pearson (korelasi product moment). Reabilitas tes juga diuji dengan menggunakan rumus product moment, tingkat kesukaran tes, dan daya beda tes. Data penelitian diperoleh melalui pretest dan posttest, angket, serta lembar observasi. Data penelitian kemudian dianalisis dengan menggunakan analisis statistik deskriptif, Anova dua arah (Two way Anova), dan uji T. Uji normalitas data dilakukan dengan uji one sample Kolmogorov Smirnov, sementara uji homogenitas dilakukan dengan teknik uji levene's.

\section{HASIL}

Berdasarkan hasil analisis data statistik pada perbedaan prestasi belajar IPS antara siswa yang diajar dengan CD komputer BSE secara klasikal dan kelompok kecil, diketahui bahwa nilai rata-rata penggunaan CD komputer BSE kelompok kecil $(79,69)$ lebih baik dibandingkan dengan kelompok klasikal $(73,78)$. Hal ini dibuktikan dengan hasil uji $\mathrm{t}=-3,172$ dengan $\mathrm{df}=22$ dan signifikansi $(0,04<0,05)$. Dengan demikian, maka hipotesis nihil ditolak. Dengan kata lain, hipotesis yang menyatakan bahwa ada perbedaan prestasi belajar IPS antara siswa yang diajar dengan CD komputer BSE secara klasikal dan kelompok kecil diterima. Ini berarti bahwa penggunaan CD Komputer BSE lebih efektif jika dilakukan dengan kelompok kecil. Secara deskriptif, jika dilihat dari masingmasing indikator hasil belajar kognitif, dapat diuraikan bahwa terjadi kenaikan nilai untuk semua indikator, yaitu: indikator mengingat, memahami, 
menerapkan, menganalisis, dan menilai. Secara khusus, untuk indikator hasil belajar IPS siswa yang diajar dengan CD komputer BSE secara klasikal, baik pada siswa yang bermotivasi tinggi maupun rendah, peningkatan nilainya cukup kecil (14,28 dan 15,52). Adapun peningkatan hasil belajar siswa yang diajar dengan CD komputer BSE secara kelompok kecil berada pada indikator baik untuk siswa yang bermotivasi tinggi maupun rendah kenaikan nilainya cukup (23,75 dan 12,81).

Berikutnya, berdasarkan hasil analisis data statistik pada perbedaan prestasi belajar IPS siswa yang diajar dengan CD komputer BSE secara klasikal antara siswa bermotivasi tinggi dan bermotivasi rendah, diketahui bahwa siswa yang diajar dengan CD komputer BSE secara klasikal pada siswa bermotivasi tinggi memiliki nilai ratarata $(76,64)$ lebih tinggi dibandingkan dengan siswa yang bermotivasi rendah $(71,17)$. Hal ini dibuktikan dengan $\mathrm{F}$ hitung $>\mathrm{F}$ tabel $(14,184>$ $4,325)$ atau nilai signifikansi dari alpha $5 \%(0,001<$ $0,050)$. Dengan demikian, hipotesis yang diterima adalah hipotesis Ha, yaitu terdapat perbedaan yang nyata pada prestasi belajar IPS antara siswa yang diajar dengan CD komputer BSE secara klasikal antara siswa yang bermotivasi tinggi dengan bermotivasi rendah.

Berdasarkan hasil analisis data statistik pada perbedaan prestasi belajar IPS siswa yang diajar dengan CD komputer BSE secara kelompok kecil antara siswa bermotivasi tinggi dan bermotivasi rendah, diketahui bahwa siswa yang bermotivasi tinggi memiliki nilai rata-rata $(89,17)$ lebih tinggi dibandingkan dengan siswa yang bermotivasi rendah $(69,36)$. Hal ini dibuktikan dengan $\mathrm{F}$ hitung $>$ F tabel $(166,298>4,325)$ atau nilai signifikansi dari alpha $5 \%(0,000<0,050)$. Dengan demikian, hipotesis yang diterima adalah hipotesis $\mathrm{Ha}$, yaitu terdapat perbedaan yang nyata pada prestasi belajar IPS antara siswa yang diajar dengan CD komputer BSE secara kelompok kecil antara siswa yang bermotivasi belajar tinggi dan bermotivasi belajar rendah. Siswa yang memiliki motivasi tinggi memiliki kecenderungan lebih baik dalam hal belajar. Mereka sudah memiliki modal dasar kemampuan kognitif yang baik, sehingga dengan dukungan strategi dan media pembelajaran yang baik, maka kemampuan kognitifnya juga akan meningkat lebih baik lagi. Siswa yang memiliki motivasi tinggi akan memiliki daya nalar yang baik dan mampu mengorganisasi materi pelajaran sehingga mereka mudah memahami pelajaran dan hasil belajarnya lebih baik. Siswa yang memiliki motivasi tinggi juga memiliki gaya belajar yang efektif dan lebih baik dalam menjaga kosentrasi belajar sehingga kemampuan kognitifnya akan lebih baik.

Berdasarkan hasil analisis data statistik pada perbedaan prestasi belajar IPS antara siswa yang diajar CD komputer BSE secara klasikal dengan kelompok kecil dilihat dari motivasi tinggi, diketahui bahwa siswa bermotivasi tinggi memiliki nilai rata-rata $(82,82)$ lebih tinggi dibandingkan siswa bermotivasi rendah $(70,26)$. Hal ini dibuktikan dengan $\mathrm{F}$ hitung $>\mathrm{F}$ tabel $(56,960>$ $4,325)$ atau nilai signifikansi dari alpha $5 \%(0,000<$ $0,050)$. Dengan demikian, hipotesis yang diterima adalah hipotesis $\mathrm{Ha}$, yaitu terdapat perbedaan yang nyata pada prestasi belajar IPS siswa yang diajar dengan CD komputer BSE secara klasikal dengan kelompok kecil dilihat dari motivasi tinggi. Pembelajaran kooperatif merupakan pembelajaran yang memungkinkan siswa untuk belajar dalam kelompok-kelompok kecil, di mana dalam kelompok tersebut terjadi interaksi antar anggota kelompok untuk memecahkan suatu permasalahan yang diberikan. Menurut Nurhadi, dkk. (2004: 61) pembelajaran kooperatif adalah pembelajaran yang secara sadar dan sistematis mengembangkan interaksi yang silih asah, silih asih, dan silih asuh antar sesama siswa sebagai latihan hidup di dalam masyarakat.

Kemudian, berdasarkan hasil analisis data statistik pada perbedaan prestasi belajar IPS antara siswa yang diajar dengan CD komputer BSE secara klasikal dengan kelompok kecil dilihat dari motivasi rendah, diketahui bahwa siswa bermotivasi rendah memiliki nilai rata-rata $(70,26)$ lebih rendah dibandingkan siswa bermotivasi tinggi $(82,82)$. Hal Ini dibuktikan nilai $\mathrm{F}$ hitung $>$ F tabel $(300,969>4,325)$ atau nilai signifikansi dari alpha $5 \%(0,000<0,050)$. Dengan demikian, hipotesis yang diterima adalah hipotesis $\mathrm{Ha}$, yaitu terdapat perbedaan yang nyata pada prestasi belajar IPS antara siswa yang diajar dengan CD komputer BSE secara klasikal dan kelompok kecil dilihat diri motivasi rendah. 
Berdasarkan hasil analisis efek interaksi antara pemanfaatan CD komputer BSE dengan motivasi belajar terhadap prestasi belajar siswa, diketahui bahwa nilai $\mathrm{F}$ hitung motivasi sebesar $9.548, \mathrm{~F}$ hitung strategi pembelajaran sebesar 238,697, dan F hitung motivasi dan pembelajaran sebesar 6,471 , dengan nilai signifikansi motivasi sebesar 0.004 , strategi pembelajaran sebesar 0.000 , dan motivasi dan pembelajaran sebesar 0,015 , yang lebih kecil daripada $\alpha=0,05$. Dengan demikian, hipotesis yang diterima adalah hipotesis $\mathrm{Ha}$, yaitu terdapat interaksi antara pemanfaatan CD komputer BSE (klasikal dan kelompok kecil) dengan motivasi belajar terhadap prestasi belajar IPS siswa. Berdasarkan hasil analisis data, ditemukan bahwa terdapat interaksi antara pemanfaatan $C D$ komputer BSE dengan motivasi belajar terhadap prestasi belajar IPS siswa. Dari rata-rata skor hasil belajar IPS, penggunaan CD komputer BSE dengan metode klasikal lebih efektif bagi siswa bermotivasi rendah, sedangkan penggunaan CD komputer BSE dengan metode kelompok kecil lebih efektif bagi siswa bermotivasi tinggi. Hal ini berarti bahwa efektivitas metode pengajaran bergantung kepada taraf motivasi, karena nilainya dalam kategori cukup dan sangat baik.

Secara umum, siswa kelas VI SDN 4 Praya merasa senang ketika mengikuti kegiatan pembelajaran dengan menggunakan media pembelajaran CD komputer BSE. Hasil analisis data angket masing-masing aspek adalah: 1) pada aspek kemudahan, 68\% siswa merasa mudah dalam pengoperasikan media pembelajaran $\mathrm{CD}$ komputer BSE. Sebaliknya, hanya 9\% siswa yang merasa kesulitan dalam pengoperasikan media pembelajaran CD komputer BSE. 2) pada aspek kemenarikan, $81 \%$ siswa merasa tertarik, $12 \%$ siswa yang kurang tertarik, dan $7 \%$ yang tidak tertarik. 3) pada aspek kesenangan, $81 \%$ siswa merasa senang (enjoy) ketika menggunakan media pembelajaran CD komputer BSE dan 20\% kurang senang. Siswa merasa senang menggunakan CD komputer BSE karena media tersebut sama seperti buku biasa, namun bentuknya diubah dalam format ebook (buku elektronik). Tampilan medianya juga menarik dan dilengkapi dengan game dan musik yang dirancang sesuai perkembangan siswa SD. Siswa tidak merasa tertekan dalam pembelajaran; mereka belajar dengan santai namun serius. Pernyataan tersebut didukung oleh data performansi, yaitu sebesar $84 \%$ siswa kelompok kecil dan $83 \%$ siswa kelompok klasikal serius dalam menggunakan media pembelajaran $\mathrm{CD}$ komputer BSE.

\section{PEMBAHASAN}

Tobin dan Gallagher (1997) yang meneliti tentang perbedaan cara pembelajaran sistem berkelompok dengan sistem kelas (klasikal) menyatakan bahwa sistem kelompok lebih baik dibandingkan dengan sistem kelas (klasikal). Hal tersebut juga didukung oleh hasil penelitian Lestari (2009) yang menunjukkan bahwa penerapan pengajaran kelompok kecil dapat meningkatkan kemampuan berpikir siswa dan dapat meningkatkan aspek motivasi belajar. Demikian pula, Astutik (2012) menyatakan bahwa terdapat perbedaan yang signifikan antara aktivitas dan hasil belajar peserta didik kelas kelompok kecil dan peserta didik klasikal. Penggunaan CD komputer BSE secara klasikal baik sekali pada siswa bermotivasi tinggi karena pembelajaran klasikal (kelompok besar) memiliki beberapa keuntungan, yaitu: alat efisien untuk ceramah, film dan demonstrasi, mengembangkan rasa aman di dalam kelompok, mempermudah untuk pengajaran konsep baru, meningkatkan otoritas guru, dan mengesankan hanya satu sumber belajar (Erman, dkk., 2001).

Pembelajaran klasikal tidak selalu kurang baik. Hal itu tergantung pada proses kegiatan yang dilaksanakan, yaitu apakah semua siswa berpartisipasi secara aktif terlibat dalam pembelajaran, pasif tidak terlibat, atau hanya mendengar dan mencatat. Pembelajaran klasikal yang paling baik adalah dengan menggunakan metode tanya jawab dengan teknik probingprompting agar partisipasi dan aktivitas siswa menjadi tinggi (Erman, dkk., 2001). Prestasi adalah hasil yang diperoleh dari sesuatu yang dilakukan, sedangkan prestasi belajar adalah penguasaan pengetahuan keterampilan terhadap mata pelajaran yang dibuktikan melalui hasil tes (Salim dan Salim, 2002). Prestasi belajar menggambarkan hasil penguasaan mahasiswa terhadap materi-materi yang telah dipelajari yang dapat dilihat dari aspek kognitif, psikomotorik, dan afektif (Gunawan, dkk., 2014). 
Krathwohl dan Anderson (2001) menjelaskan bahwa prestasi belajar mahasiswa dapat tercermin dalam dimensi proses kognitif mahasiswa. Dimensi proses kognitif ini meliputi enam tingkatan Taksonomi Bloom yang telah direvisi, yakni: mengingat (remember), memahami/mengerti (understand), menerapkan (apply), menganalisis (analyze), mengevaluasi (evaluate), dan menciptakan (create). Prestasi belajar merupakan hasil interaksi berbagai faktor (Mulyasa, 2005). Faktor-faktor yang mempengaruhi proses dan hasil belajar dapat digolongkan menjadi empat yaitu bahan atau materi yang dipelajari, lingkungan, faktor instrumental, dan kondisi mahasiswa (Mulyasa, 2005). Faktor-faktor tersebut akan memberikan kontribusi tertentu terhadap prestasi belajar. Berdasarkan pengertian-pengertian di atas disimpulkan bahwa prestasi belajar adalah hasil yang didapatkan dari pembelajaran yang mengarah pada proses kognitif dan merupakan hasil interaksi dari beberapa faktor antara lain bahan atau materi yang dipelajari, lingkungan, faktor instrumental, dan kondisi mahasiswa (Mulyasa, 2005).

\section{SIMPULAN DAN SARAN}

Berdasarkan dari temuan penelitian dan pembahasan di atas, dapat disimpulkan beberapa hal sebagai berikut: (1) CD Komputer BSE lebih efektif untuk digunakkan pada kelompok kecil; (2) penggunaan CD komputer BSE secara klasikal baik sekali pada siswa yang bermotivasi tinggi; (3) CD komputer BSE sangat baik untuk digunakan pada kelompok kecil, terutama pada siswa yang bermotivasi tinggi; (4) dilihat dari motivasi tinggi penggunaan $\mathrm{CD}$ pembelajaran BSE adalah secara kelompok kecil, sedangkan dilihat dari motivasi rendah kedua metode pembelajaran yang paling efektif penggunaan CD pembelajaran BSE adalah secara klasikal; (5) hasil analisis menunjukkan ada interaksi siswa yang diajar CD komputer BSE secara kelompok kecil lebih efektif dari pada pembelajaran klasikal baik pada tingkat motivasi ini berarti efektivitas metode pengajaran bergantung kepada taraf motivasi, karena nilainya dalam katagori cukup dan sangat baik; dan (6) siswa Kelas IV SDN 4 Praya Kabupaten Lombok Tengah merasa mudah, merasa tertarik, dan merasa senang ketika mengikuti kegiatan pembelajaran dengan menggunakan CD komputer BSE.
Berdasarkan kesimpulan, diajukan saran / rekomendasi: bagi para guru, sangat disarankan untuk menggunakan BSE dalam pembelajaran IPS. Hal ini karena BSE sangat efektif untuk membangkitkan minat belajar siswa, meningkatkan kepercayaan diri siswa, meningkatkan daya tarik belajar/perhatian siswa, dan meningkatkan motivasi belajar siswa, dapat merangsang siswa untuk berfikir kreatif dan inspiatif, meningkatkan hasil belajar siswa, mudah didapatkan melalui jaringan internet, menghemat biaya dan tenaga, mudah disalin dan digabungkan ke dalam dokumen lain, menghindari penggunaan tenaga dalam mencatat, dan dapat dibaca dimana saja. Bagi sekolah atau lembaga pendidikan, hasil penelitian ini dapat dijadikan sebagai salah satu dasar dalam mengambil kebijakan untuk menyediakan fasilitas sekolah yang memadai dan menyediakan jaringan internet online di dalam penggunaan dan pengembangan media pembelajaran secara terpadu antar bidang studi yang dikemas dalam bentuk e-book/CD komputer. Bagi Dinas Pendidikan Kab. Lombok Tengah, hasil penelitian ini diharapkan dapat memberikan dasar kebijakan lebih lanjut mengenai sumber belajar alternatif, yaitu $C D$ komputer BSE dapat diprogramkan di semua satuan pendidikan baik tingkat dasar maupun menengah agar tujuan utama pendidikan dapat berjalan sesuai yang diharapkan. Bagi peneliti lain, hasil penelitian ini dapat dijadikan sebagai salah satu acuan dalam mengembangkan media pembelajaran, khususnya media pembelajaran berbasis CD komputer.

\section{DAFTAR RUJUKAN}

Astutik, P. 2012. Pengaruh Peggunaan Media CD Interaktif terhadap Aktivitas dan Hasil Belajar IPS Peserta Didik Kelas IV SDN Rejosari 01 Bantur. Skripsi tidak diterbitkan. Malang: Jurusan KSDP FIP UM.

Gunawan, I., dan Benty, D. D. N. 2007. Musyawarah Guru Mata Pelajaran dan Kemampuan Mengelola Kelas untuk Meningkatkan Motivasi Belajar Siswa. Manajemen Pendidikan, 20(1), 21-31.

Gunawan, I., Suraya, S. N., dan Tryanasari, D. 2014. Pengaruh Supervisi Pengajaran dan Kemampuan Guru Mengelola Kelas terhadap Motivasi Belajar Siswa. Ilmu Pendidikan Jurnal Kajian Teori dan Praktik 
Kependidikan, 41(1), 44-52.

Irawan, Z., Sari, M. E., dan Setyoningrum, M.

U. 2010. Analisis Implementasi Kebijakan

Buku Sekolah Elektronik (BSE) Kementerian

Pendidikan Nasional di Sekolah Menengah

Atas (SMA) Kota Yogyakarta (Studi kasus di SMA Negeri 8 dan SMA Negeri 9 Yogyakarta), (Online), (https://journal.uny.ac.id/index.php/ pelita/article/viewFile/4298/3723), diakses 2 Mei 2015.

Krathwohl, D. R. dan Anderson, L. W. 2001. A Taxonomy for Learning, Teaching, and Assessing: A Revision of Bloom's Taxonomy of Educational Objectives. New York: Addison Wesley Longman, Inc.

Lestari, D.K. 2009. Penerapan Pengajaran Kelompok Kecil dalam Meningkatkan Kemampuan Berpikir dan Motivasi Belajar Siswa Kelas X MA Al-Hidayah Donowarih Karangploso Malang pada Mata Pelajaran Biologi. Skripsi tidak diterbitkan. Malang: Jurusan Biologi FMIPA UM.
Mulyasa, E. 2005. Implementasi Kurikulum 2004: Panduan Pembelajaran KBK. Bandung: PT Remaja Rosdakarya.

Nurhadi, dkk. 2004. Pembelajaran Kontekstual dan Penerapannya dalam KBK. Malang: UM Press.

Salim, P, dan Salim, Y. 2002. Kamus Bahasa Indonesia Kontemporer. Jakarta: Modern English Press.

Suherman, E., dkk. 2001. Strategi Pembelajaran Matematika Kontemporer. Bandung: JICAUPI.

Tobin, K. dan Gallagher, J. J. 1987. The Role of Target Students in the Science Classroom. Journal of Research in Science Teaching, 24(1): 61-75. 